This Section of Epidemiology and Psychiatric Sciences regularly appears in each issue of the Journal to stress the relevance of epidemiology for behavioral neurosciences, reporting the results of studies that explore the use of an epidemiological approach for providing a better understanding of the neural basis of major psychiatric disorders and, in turn, the utilisation of the behavioural neurosciences for promoting innovative epidemiological research.

The final scope is to help the translation of most relevant research findings into every-day clinical practice. These contributions are written in house by the journal's editorial team or commissioned by the Section Editor (no more than 1000 words, short unstructured abstract, 4 key-words, one Table or Figure and up to ten references).

Paolo Brambilla, Section Editor

\title{
Epidemiological and clinical aspects will guide the neuroimaging research in bipolar disorder
}

\author{
J. Houenou ${ }^{1,2,3,4 *}$, C. Perlini ${ }^{5}$ and P. Brambilla ${ }^{6,7}$ \\ ${ }^{1}$ UNIACT, Neurospin, I2BM, CEA Saclay, Gif-Sur-Yvette, France \\ 2 INSERM, U955, IMRB, Team15 'Equipe psychopathologie et Génétique des maladies psychiatriques', Créteil F-94000, France \\ ${ }^{3}$ Fondation Fondamental, Créteil F-94010, France \\ ${ }^{4}$ AP-HP, Hôpitaux Universitaires Mondor, DHU PePsy, Pôle de Psychiatrie, Créteil F-94000, France \\ ${ }^{5}$ Department of Public Health and Community Medicine, Section of Clinical Psychology, Inter-University Center for Behavioural Neurosciences \\ (ICBN), University of Verona, Verona, Italy \\ ${ }^{6}$ Department of Experimental \& Clinical Medicine, ICBN, University of Udine, Udine, Italy \\ ${ }^{7}$ IRCCS 'E. Medea' Scientific Institute, UDGEE, Udine, Italy
}

\begin{abstract}
Although neurobiological mechanisms of bipolar disorder (BD) are still unclear, neural models of the disease have recently been conceptualised thanks to neuroimaging. Indeed, magnetic resonance imaging (MRI) studies investigating structural and functional connectivity between different areas of the brain suggest an altered prefrontal-limbic coupling leading to disrupted emotional processing in $\mathrm{BD}$, including uncinate fasciculus, amygdala, parahippocampal cortex, cingulate cortex as well corpus callosum. Specifically, these models assume an altered prefrontal control over a hyperactivity of the subcortical limbic structures implicated in automatic emotional processing. This impaired mechanism may finally trigger emotional hyper-reactivity and mood episodes. In this review, we first summarised some key neuroimaging studies on BD. In the second part of the work, we focused on the heterogeneity of the available studies. This variability is partly due to methodological factors (i.e., small sample size) and differences among studies (i.e., MRI acquisition and post-processing analyses) and partly to the clinical heterogeneity of BD. We finally outlined how epidemiological studies should indicate which risk factors and clinical dimensions of BD are relevant to be studied with neuroimaging in order to reduce heterogeneity and go beyond diagnostic categories.
\end{abstract}

Received 19 August 2014; Revised 25 November 2014; Accepted 25 November 2014; First published online 16 January 2015

Key words: Biological markers, bipolar disorder, brain imaging techniques, epidemiology, neuroanatomy.

Neurobiological mechanisms of bipolar disorder (BD) are still unclear and subject to debate. One way to

* Address for correspondence: Dr J. Houenou, INSERM U955, IMRB, Equipe 15 "Psychiatrie Génétique", 40 rue de Mesly, Créteil 94000, France.

(Email: josselin.houenou@inserm.fr) decipher these mechanisms is the use of neuroimaging. Magnetic resonance imaging (MRI) and positron emission tomography (PET) both allow the study of structural and functional alterations in BD. Structural neuroimaging techniques include anatomical T1 and diffusion weighted MRI. Studies of BD patients with T1 MRI revealed alterations in volume of prefrontal 
and limbic regions such as the amygdala, the parahippocampal and the cingulate cortices (Houenou et al. 2012). Diffusion MRI studies identified in BD microstructural white matter abnormalities in prefrontallimbic (uncinate), limbic (cingulum) and also callosal tracts (Sarrazin et al. 2014). Most of the functional neuroimaging studies used emotion processing paradigms during functional MRI (fMRI) and generally reported hyperactivity of the subcortical limbic structures associated with a hypoactivation of prefrontal cortices, even in euthymic patients (Delvecchio et al. 2013). These results have led to the conceptualisation of neural models of BD (Table 1): in response to emotional stimuli, these models assume a hyperactivity of the subcortical limbic structures implicated in automatic emotional processing (such as the amygdala and the parahippocampal cortex). Owing to altered structural and functional connectivity between ventral prefrontal networks and these limbic regions, the modulation of the activity of the amygdala by the prefrontal cortices would be inefficient. This altered prefrontal control over an overactive limbic system may trigger emotional hyperreactivity and mood episodes (Phillips \& Swartz, 2014).

Despite these promising results and neural models of $\mathrm{BD}$, several caveats remain. The aetiology of the identified abnormalities (genetic or environmental; neurodevelopmental or neurodegenerative) is one of these. Their specificity (as compared to unipolar depression or schizophrenia) is a second one. Another unsolved issue is the heterogeneity of the results between studies. Recent meta-analytic analyses identified this heterogeneity as large (Selvaraj et al. 2012). Three types of factors can explain it: first, the small samples used lead to the inflation of type I error (false positives) and low reproducibility of the results (Button et al. 2013). Second, methodological factors such as different MRI scanners, field strengths, acquisition sequences or processing software can lead to different results between studies. Third, clinical differences between the samples may account for a significant proportion of this heterogeneity. Potential different subtypes of BD can arise from various clinical features: differences in age at onset, presence/absence of suicide attempts, BD type I or II, presence/absence of psychotic symptoms during episode, variability in emotional reactivity, medication effects (lithium is supposed to have a neuroprotective effect), comorbidities (especially substance use and anxiety disorders), presence/absence of family history of mood disorders or presence/absence of environmental factors, such as childhood trauma, urbanicity during upbringing, migration. The potential sources of clinical heterogeneity are thus numerous and diverse.

We suggest two different strategies to understand the link between these clinical factors and brain alterations. First, the recruitment of very large samples will allow the study of this link in BD. To this regard, a few recent studies have used sample sizes $N>100$ which had the statistical power to explore the impact of psychotic symptoms (Brandt et al. 2014; Sarrazin et al. 2014). Their results support that BD with psychotic features may be a subtype of BD with specific neurobiological basis, evidenced by poorer white matter integrity. Second, we suggest the use of innovative clinical approaches for phenotyping samples in neuroimaging studies. Among these, one of the most promising is the dimensional clinical assessment of BD and related disorders. Its aim is to identify biologically based clinical dimensions that will be more relevant to the study of BD and should be independent of diagnostic categories. The National Institute of Mental Health has recently advocated for this strategy, with its Research Domain Criteria initiative. A very recent study found that fractional anisotropy (a measure of the integrity of white matter tracts) in the left superior longitudinal fasciculus correlated with the 'SchizoBipolar scale' across diagnoses of schizophrenia or BD with psychotic features. This scale is a measure of the dimensional continuum between schizophrenia and BD (Skudlarski et al. 2013). This shows the feasibility of correlating a dimensional measure to a neuroimaging variable across diagnoses. Another example is executive dysfunction: Shpeherd et al. recently found that patients (with BD or schizophrenia) with executive deficits had grey matter reduction in frontal and precentral gyri compared to patients without executive dysfunction (Shepherd et al. 2014).

The choice of the pertinent clinical dimensions to correlate with MRI data is determinant. Despite increasing sample sizes, neuroimaging studies will not be able to test many dimensions, due to multiple comparison issues and feasibility reasons. Epidemiological and clinical studies will thus have a critical role in suggesting what may be the 'core' clinical dimensions to study. One example is the recent identification of emotional hyper-reactivity as a candidate of such a biologically based core dimension of mood disorders (Phillips \& Kupfer, 2013). Several lines of evidence point towards a critical role of emotional reactivity in BD and mood switches. Emotional reactivity is increased in patients with BD across thymic states, but also in other disorders such as borderline personality. Studies on neuroticism (that can be conceptualised as emotional reactivity to negative stimuli) suggest that emotional reactivity to negative stimuli is associated with neuroanatomical and functional characteristics in the limbic network. It remains to be tested if emotional reactivity is a clinical dimension associated with changes in the limbic system across diagnoses. Another example of this approach is the recent identification of neural 
Table 1. Some selected key neuroimaging studies and models of BD

\begin{tabular}{|c|c|c|c|}
\hline Study & Method/sample & $\begin{array}{l}\text { Main results in patients with } \mathrm{BD} \\
\text { compared with controls }\end{array}$ & Interest \\
\hline $\begin{array}{l}\text { Brandt et al. } \\
\quad(2014)\end{array}$ & $\begin{array}{l}\text { Working memory (n-back) fMRI } \\
\text { study in } 100 \text { patients with BD, } \\
100 \text { patients with } \\
\text { schizophrenia and } 100 \\
\text { controls }\end{array}$ & $\begin{array}{l}\text { Patients with BD had intermediate } \\
\text { activation (between patients with } \\
\text { schizophrenia and controls). } \\
\text { History of psychosis in BD was } \\
\text { associated with brain activation }\end{array}$ & $\begin{array}{l}\text { Large sample size } \\
\text { Evidence from fMRI for history of } \\
\text { psychosis in BD as a relevant } \\
\text { phenotype }\end{array}$ \\
\hline $\begin{array}{l}\text { Delvecchio } \\
\text { et al. (2013) }\end{array}$ & $\begin{array}{l}\text { Meta-analysis of } 29 \text { studies on } \\
\text { affect processing fMRI studies } \\
\text { in BD or schizophrenia }\end{array}$ & $\begin{array}{l}\text { Overactivation within the } \\
\text { parahippocampus/amygdala and } \\
\text { reduced engagement in the } \\
\text { prefrontal cortex }\end{array}$ & $\begin{array}{l}\text { Discusses the diagnosis specificity } \\
\text { of fMRI findings in BD compared } \\
\text { to schizophrenia (in which } \\
\text { underactivation in the limbic } \\
\text { network was found) }\end{array}$ \\
\hline $\begin{array}{l}\text { Houenou } \\
\text { et al. (2012) }\end{array}$ & $\begin{array}{l}\text { Meta-analyses of } 15 \mathrm{VBM} \text { and } 13 \\
\text { emotional processing fMRI } \\
\text { studies }\end{array}$ & $\begin{array}{l}\text { Increased activation in ventral limbic } \\
\text { regions; decreased activation and } \\
\text { diminution of grey matter in a } \\
\text { cortical cognitive network }\end{array}$ & $\begin{array}{l}\text { Summarises the previous literature } \\
\text { and supports neural models } \\
\text { of } \mathrm{BD}\end{array}$ \\
\hline $\begin{array}{l}\text { Phillips \& } \\
\text { Swartz } \\
\text { (2014) }\end{array}$ & $\begin{array}{l}\text { Critical review of the } \\
\text { neuroimaging literature of } \mathrm{BD}\end{array}$ & $\begin{array}{l}\text { Dysfunction in prefrontal cortical, } \\
\text { subcortical limbic and reward } \\
\text { processing networks }\end{array}$ & $\begin{array}{l}\text { One of the most recent neural } \\
\text { models of BD } \\
\text { Stresses the abnormalities present in } \\
\text { brain circuits in BD }\end{array}$ \\
\hline $\begin{array}{l}\text { Sarrazin et al. } \\
\qquad(2014)\end{array}$ & $\begin{array}{l}\text { Whole brain tractography study } \\
\text { of } 118 \text { patients and } 86 \text { controls }\end{array}$ & $\begin{array}{l}\text { Decreased FA in the corpus callosum, } \\
\text { cingulum and arcuate. Patients with } \\
\text { psychotic features had a lower } \\
\text { mean FA value than those without } \\
\text { in the corpus callosum }\end{array}$ & $\begin{array}{l}\text { Large sample size } \\
\text { Brings evidence for BD with } \\
\text { psychotic features as a specific } \\
\text { subtype }\end{array}$ \\
\hline $\begin{array}{l}\text { Selvaraj et al. } \\
\qquad(2012)\end{array}$ & $\begin{array}{l}\text { Meta-analysis of } 16 \text { VBM studies } \\
\text { in BD }\end{array}$ & $\begin{array}{l}\text { Reduced grey matter in a single } \\
\text { cluster (right ventral prefrontal } \\
\text { cortex, insula, temporal cortex, } \\
\text { claustrum). Large between-studies } \\
\text { heterogeneity throughout the brain }\end{array}$ & $\begin{array}{l}\text { Demonstrates the heterogeneity } \\
\text { between structural studies in BD }\end{array}$ \\
\hline $\begin{array}{l}\text { Skudlarski } \\
\text { et al. (2013) }\end{array}$ & $\begin{array}{l}\text { Diffusion MRI study in } 513 \\
\text { subjects including patients } \\
\text { with psychotic BD, } \\
\text { schizophrenia and their } \\
\text { relatives }\end{array}$ & $\begin{array}{l}\text { Lower FA in multiple regions. FA in } \\
\text { the left superior longitudinal } \\
\text { fasciculus correlated with the } \\
\text { 'Schizo-Bipolar scale' across } \\
\text { diagnoses }\end{array}$ & $\begin{array}{l}\text { Shows the interest of correlating a } \\
\text { dimensional measure to a } \\
\text { neuroimaging variable across } \\
\text { diagnoses }\end{array}$ \\
\hline
\end{tabular}

BD, bipolar disorder; FA, fractional anisotropy; VBM, voxel-based morphometry.

correlates of the epidemiological risk factors for schizophrenia such as urban upbringing, migration, cannabis use or childhood trauma (Lederbogen et al. 2011). Although most of these risk factors are shared with $\mathrm{BD}$, we still do not know if these neural correlates are valid across diagnoses.

In conclusion, neuroimaging studies have allowed us to build models of the neural mechanisms of BD. A deeper understanding of how risk factors and clinical dimensions impact the brain and lead to mental disorders such as BD necessitate a strong collaboration between epidemiologists, clinicians and neuroscientists.

\section{Acknowledgements}

None.

\section{Financial Support}

J.H. was partially supported by the Investissements d'Avenir programs managed by the ANR under references ANR-11-IDEX-0004- and ANR-10-COHO-10-01 P.B. was partially supported by grants from the Italian Ministry of Health (grant no. GR-2010-2319022; GR-2010-2316745; RF-2011-02352308).

\section{Conflict of Interest}

None.

\section{Ethical Standards}

The authors declare that no human or animal experimentation was conducted for this work. 


\section{References}

Brandt CL, Eichele T, Melle I, Sundet K, Server A, Agartz I, Hugdahl K, Jensen J, Andreassen OA (2014). Working memory networks and activation patterns in schizophrenia and bipolar disorder: comparison with healthy controls. British Journal of Psychiatry 204, 290-8.

Button KS, Ioannidis JP, Mokrysz C, Nosek BA, Flint J, Robinson ES, Munafo MR (2013). Power failure: why small sample size undermines the reliability of neuroscience. Nature Reviews Neuroscience 14, 365-76.

Delvecchio G, Sugranyes G, Frangou S (2013). Evidence of diagnostic specificity in the neural correlates of facial affect processing in bipolar disorder and schizophrenia: a meta-analysis of functional imaging studies. Psychological Medicine 43, 553-69.

Houenou J, D'Albis MA, Vederine FE, Henry C, Leboyer M, Wessa M (2012). Neuroimaging biomarkers in bipolar disorder. Frontiers in Bioscience (Elite Edition) 4, 593-606.

Lederbogen F, Kirsch P, Haddad L, Streit F, Tost H, Schuch P, Wust S, Pruessner JC, Rietschel M, Deuschle M, Meyer-Lindenberg A (2011). City living and urban upbringing affect neural social stress processing in humans. Nature 474, 498-501.

Phillips ML, Kupfer DJ (2013). Bipolar disorder diagnosis: challenges and future directions. Lancet 381, 1663-71.

Phillips ML, Swartz HA (2014). A critical appraisal of neuroimaging studies of bipolar disorder: toward a new conceptualization of underlying neural circuitry and a road map for future research. The American Journal of Psychiatry 171, 829-43.

Sarrazin S, Poupon C, Linke J, Wessa M, Phillips M, Delavest M, Versace A, Almeida J, Guevara P, Duclap D, Duchesnay E, Mangin JF, Le Dudal K, Daban C, Hamdani N, D'Albis MA, Leboyer M, Houenou J (2014). A multicenter tractography study of deep white matter tracts in bipolar I disorder: psychotic features and interhemispheric disconnectivity. JAMA Psychiatry 71, 388-96.

Selvaraj S, Arnone D, Job D, Stanfield A, Farrow TF, Nugent AC, Scherk H, Gruber $O$, Chen $X$, Sachdev PS, Dickstein DP, Malhi GS, Ha TH, Ha K, Phillips ML, Mcintosh AM (2012). Grey matter differences in bipolar disorder: a meta-analysis of voxel-based morphometry studies. Bipolar Disorders 14, 135-45.

Shepherd A, Quide Y, Laurens K, O'Reilly N, Rowland J, Mitchell P, Carr V, Green M (2014). Shared intermediate phenotypes for schizophrenia and bipolar disorder: neuroanatomical features of subtypes distinguished by executive dysfunction. Journal of Psychiatry and Neurosciences 39(5), 130283.

Skudlarski P, Schretlen DJ, Thaker GK, Stevens MC, Keshavan MS, Sweeney JA, Tamminga CA, Clementz BA, O'Neil K, Pearlson GD (2013). Diffusion tensor imaging white matter endophenotypes in patients with schizophrenia or psychotic bipolar disorder and their relatives. The American Journal of Psychiatry 170, 886-98. 